\title{
Crestamento foliar, nova sintomatologia em al godoeiro causada por Xanthomonas axonopodis pv. malvacearum
}

\author{
Valdemar A tílio M alavolta J r. ${ }^{1}$, Suzete A parecida L anza D estéfano², L uís O távio Saggion B eriam², \\ M ariaA ngélica Pizzinatto ${ }^{1}$, Edivaldo $\mathrm{Cia}^{1}$
}

${ }^{1}$ Instituto A gronômico/ A PTA, Caixa Postal 28, 13001-970, Campinas, SP; ${ }^{2}$ Instituto Biológico/ A PTA, Campinas, SP.

A utor para correspondência: Valdemar A. M alavolta J r.

Data de chegada: 16/05/2006. A ceito para publicação em: 11/01/2008

\section{RESUM O}

M alavolta Júnior, V.A.; Destéfano, S. A . L.; B eriam; L. O. S.; Pizzinatto, M .A .; Cia, E . C restamento foliar, nova sintomatologia em al godoeiro causada por Xanthomonas axonopodis pv. malvacearum. Summa Phytopathologica, v.34, n.2, p.168-171, 2008

Foi observada recentemente no Estado de São Paulo uma nova sintomatologia em algodoeiro CV. M akina, IA C 24 e Detaopal, causada por Xanthomonas axonopodis pv. malvacearum (Xam), denominada "crestamento foliar". Caracteriza-se por crestamento foliar, geralmente acompanhado por halo clorótico, podendo também causar sintomas de " $V$ " invertido, a partir dos bordos foliares. Linhagens de
$X$ am foram comparadas, por meio de testes de patogenicidade, bioquímicos, sorológicos, culturais e PCR-RFLP da região espaçadora 16S-23S DNA r. Independentemente do tipo de sintoma, as linhagens apresentaram características e perfis idênticos aos apresentados pela linhagem tipo, confirmando a identidade dos isolados como Xanthomonas axonopodis pv. malvacearum.

Palavras-chave adicionais: bacteriose em algodoeiro, G ossypium hirsutum

ABSTRACT

M alavolta Júnior, V.A.; D estéfano, S. A . L.; B eriam; L. O. S.; Pizzinatto, M .A .; Cia, E. Cotton leaf blight, a new symptomatology caused by Xanthomonas axonopodis pv. malvacearum. Summa Phytopathologica, v.34, n.2, p.168-171, 2008

Recently a new symptomatology on cotton plants (cv. Makina, IAC 24 and Deltaopal) caused by Xanthomonas axonopodis pv. malvacearum (Xam) was observed in São Paulo state, Brazil, and named "bacterial leaf blight". The symptom was characterized by leaf blight, generally exhibiting chlorotic haloes and sometimes showing V-shaped lesions beginning at the leaves' border. Strains of
$\mathrm{X}$ am responsible for typical angular leaf spots and bacterial leaf blight were compared through pathological, biochemical, serological, cultural and RFLP-PCR tests of the 16S-23S spacer region. Independently of the symptom type, the strains exhibited characteristics and profiles that were identical to those exhibited by the type strain, which confirms the isolates identity Xanthomonas axonopodis pv. malvacearum

Additional keywords: cotton bacteriosis, Gossypium hirsutum.

A bactéria Xanthomonas axonopodis pv. malvacearum (Xam) ocorre nas principais regiões produtoras de algodão de nosso país, e é responsável por danos econômicos à cul tura, afetando capul hos, caule, ramos e fol has. $\mathrm{N}$ as fol has, os sintomas ocasionados são caracterizados como manchas angulares e necrose das nervuras $(1,2,8)$. Recentemente, foi observado em cultivo de al godoeiro (cvs. M akina, IA C e D eltaopal) Iocalizado no Centro Experimental de Campinas, IAC, no Estado de São Paulo, sintomas de crestamento foliar similares àquel es causados por fungos dos gêneros $F$ usarium e Verticillium (6). Essa sintomatologia geralmente é acompanhada por halo cl orótico, podendo também causar sintomas de "V" invertido, a partir dos bordos foliares, com a penetração da bactéria provavel mente via hidatódios. A região afetada torna-se quebradiça e pardacenta, havendo abscisão das folhas severamente atacadas. D os materiais coletados foram isoladas bactérias do gênero Xanthomonas.

Face à constatação dessa nova sintomatologia, este estudo teve por objetivo confirmar a caracterização das bactérias isoladas de fol has de al godoeiro com sintomas de crestamento foliar, por meio de testes de patogenicidade, bioquímicos, culturais, sorológicos, moleculares (PCR-R FL P da região espaçadora 16S-23S D N A r) e de sensibilidade "in vitro" a antibióticos de uso agrícola.

Quatro linhagens isoladas de folhas de algodoeiro, sendo duas provenientes de lesões angulares características (IBSBF 1912 e 2003) e duas provenientes de sintomas em " $\mathrm{V}$ " invertido e crestamento foliar (IBSBF 1911 e 1913) foram comparadas com a linhagem patotipo de $X$ am (IBSB F-1773 $)$. Os experimentos foram conduzidos em casade-vegetação e laboratórios do Instituto A gronômico e do Instituto Biológico, localizados em Campinas, SP.

Nos testes de patogenicidade, foram utilizadas plantas de al godoeiro das cultivares D eltaopal, I A C 24 e M akina, com 20 dias de idade. Essas cultivares diferem quanto à resistência a Xam, sendo consideradas, respectivamente, como resistente, moderadamente resistente e suscetível. Para cada um dos tratamentos (linhagem bacteriana, cultivar e método de inoculação) foram utilizadas plantas 

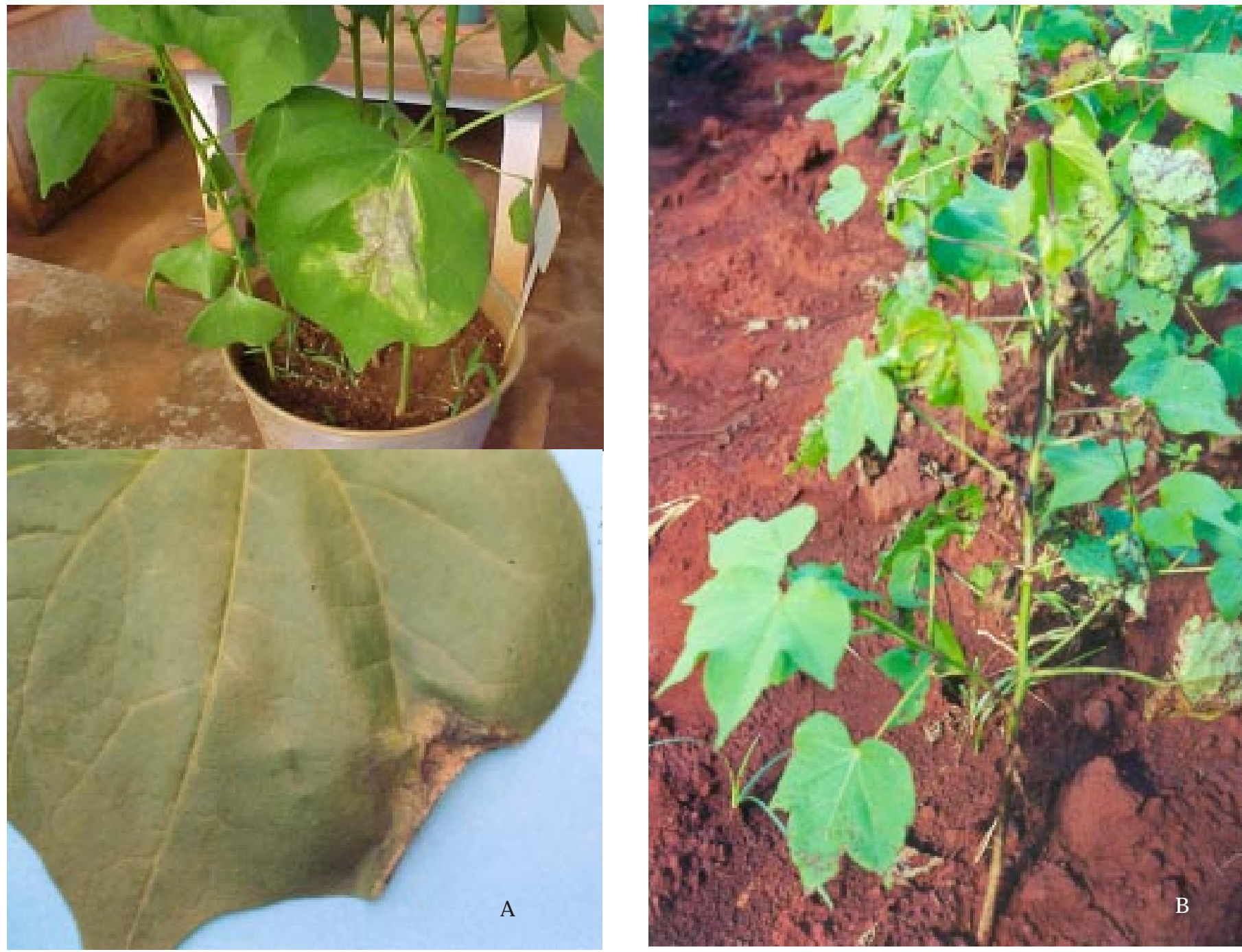

Figura 1. Sintomas de crestamento foliar em algodoeiro causado por Xanthomonas axonopodis pv. malvacearum (A. Inoculação artificial; B. Infecção natural)

contidas em três vasos, cada qual com 3-4 mudas. Folhas totalmente expandidas destas cultivares foram inoculadas, separadamente, por meio de ferimentos por agulhas múltiplas previamente mergulhadas em suspensão bacteriana $\left(5 \times 10^{8} \mathrm{UFC} / \mathrm{mL}\right)$ ou por pulverização foliar com pressão de $1,0 \mathrm{kgf} / \mathrm{cm}^{2}$, até o ponto de escorrimento, utilizando uma suspensão de $10^{7} \mathrm{UFC} / \mathrm{mL}$, sem entretanto causar anasarca dos tecidos foliares. Plantas controle foram tratadas com água destilada esterilizada. 0 material inoculado foi mantido em casa-de-vegetação, sob câmara úmida durante $72 \mathrm{~h}$. A s linhagens empregadas (IBSB F $1911,1912,1913$ e 2003) foram capazes de reproduzir tanto os sintomas típicos de mancha angular como os de crestamento foliar, independentemente da resistência genética do hospedeiro.

Os testes bioquímicos e culturais foram conduzidos segundo metodologia descrita por Schaad et al. (7), para o gênero Xanthomonas. Os resultados desses testes permitiram confirmar a identificação dos isolados de algodoeiro, originários de lesões angulares e lesões em " $\mathrm{V}$ ", como pertencentes ao gênero Xanthomonas, e estão sumarizados na TABELA 1.

Suspensões bacterianas em solução sal ina das linhagens constantes da TA B ELA 1 foram testadas como antígenos em ensaios sorológicos de dupla difusão em ágar contra antissoro policlonal produzido para a linhagem IBSB F-1881 deX. a. pv. malvacearum, pertencente à coleção de antissoros do Instituto Biológico. As suspensões também foram testadas contra soro normal, control e negativo das reações sorológicas. 0 s resultados desses testes mostraram reação de identidade total entre as linhagens causadoras de lesões angulares típicas, aquelas causadoras de sintomas de crestamento foliar e a linhagem patotipo de Xam.

A lém das linhagens IB SB F 1911, 1912, 1913 e 2003 isoladas de al godoeiro, as linhagens tipo de X. C. pv. campestris (IBSB F-1163'), $X$. a. pv. axonopodis (IBSBF-1444' ) e a patotipo de X. a. pv. malvacearum (TABELA 1), foram incluídas para fins comparativos nos experimentos de amplificação por PCR. As extrações de DNAs foram efetuadas de acordo com Pitcher et al. (5) e os experimentos de amplificação da região espaçadora 16S-23S DNAr, de acordo com Destéfano \& Rodrigues $N$ eto (3). Os produtos de PCR obtidos foram digeridos com as seguintes enzimas de restrição: Afa I, Alu I, D de I, $\mathrm{H}$ ae III e H pa II. A observação dos perfis de restrição foi realizada por meio de eletroforese em gel de agarose $3 \%$. Os géis foram tratados com brometo de etídeo $(10 \mathrm{mg} / \mathrm{mL})$, visual izados sob luz U.V. e fotografados em sistema digital. A amplificação da região espaçadora produziu um único fragmento de aproximadamente $1 \mathrm{~kb}$ para todas as linhagens testadas. As digestões dos produtos de PCR com Afa I geraram fragmentos de 500 e 490 pares de bases (pb); com Alu l, os fragmentos obtidos foram de aproximadamente 260, 210, 120 e $100 \mathrm{pb}$. Nas 
TABELA 1. Linhagens bacterianas e resultados dos testes comparativos entre isolados de algodoeiro, Xanthomonas axonopodis pv. malvacearum $(\mathrm{Xam})$, Xanthomonas campestris pv. campestris (Xcc) e Xanthomonas axonopodis pv. axonopodis (Xaa).

\begin{tabular}{|c|c|c|c|c|c|c|c|c|}
\hline \multicolumn{9}{|l|}{ TESTES } \\
\hline Bactéria & $\mathrm{Xam}$ & $\mathrm{X} a \mathrm{~m}$ & $\mathrm{Xam}$ & $\mathrm{Xam}$ & $\mathrm{Xam}$ & $\mathrm{X}$ am & $\mathrm{X}$ aа & $X \subset c$ \\
\hline Número de A cesso IBSBF & $1733^{P}$ & 1881 & 1911 & 1912 & 1913 & 2003 & $1444^{\top}$ & $1163^{\top}$ \\
\hline Hospedeiro & Gossypium sp. & $\begin{array}{l}\text { Gossypium } \\
\text { hirsutum }\end{array}$ & $\begin{array}{l}\text { Gossypium } \\
\text { hirsutum }\end{array}$ & $\begin{array}{l}\text { Gossypium } \\
\text { hirsutum }\end{array}$ & $\begin{array}{l}\text { Gossypium } \\
\text { hirsutum }\end{array}$ & $\begin{array}{l}\text { Gossypium } \\
\text { hirsutum }\end{array}$ & $\begin{array}{l}\text { Axonopus } \\
\text { scopanicus }\end{array}$ & $\begin{array}{l}\text { Brassica } \\
\text { oleracea var. } \\
\text { gemmifera }\end{array}$ \\
\hline$\overline{0 / F}$ & Oxidativo & NR & Oxidativo & Oxidativo & Oxidativo & Oxidativo & NR & NR \\
\hline Reação de Gram & -1 & NR & - & - & - & - & NR & NR \\
\hline Oxidase & - & NR & - & - & - & - & NR & NR \\
\hline Catalase & - & NR & - & - & - & - & NR & NR \\
\hline U réase & - & NR & - & - & - & - & NR & $N R$ \\
\hline $\begin{array}{l}\text { Dulcitol, á-m-D-glicoside, m-inositol, } \\
\text { rhamnose, salicina, D(-)sorbitol }\end{array}$ & - & NR & - & - & - & - & NR & NR \\
\hline \multicolumn{9}{|l|}{ Utilização de ácidos orgânicos } \\
\hline A cetato, citrato, succinato & + & NR & + & + & + & + & NR & NR \\
\hline Oxalato, tartarato & - & NR & - & - & - & - & NR & NR \\
\hline
\end{tabular}

${ }^{\top}$ - Linhagem Tipo, ${ }^{P}$ - Linhagem Patotipo, IBSBF - Coleção de Culturas de Fitobactérias do Instituto Biológico, Campinas, SP, ATCC - A merican Type Culture Collection, Rockville, M aryland, USA

ICM P - International Collection of M icroorganisms from Plants, A uckland, New Zealand

1 - resultado positivo; ${ }^{2}+$ resultado negativo, NR não realizado

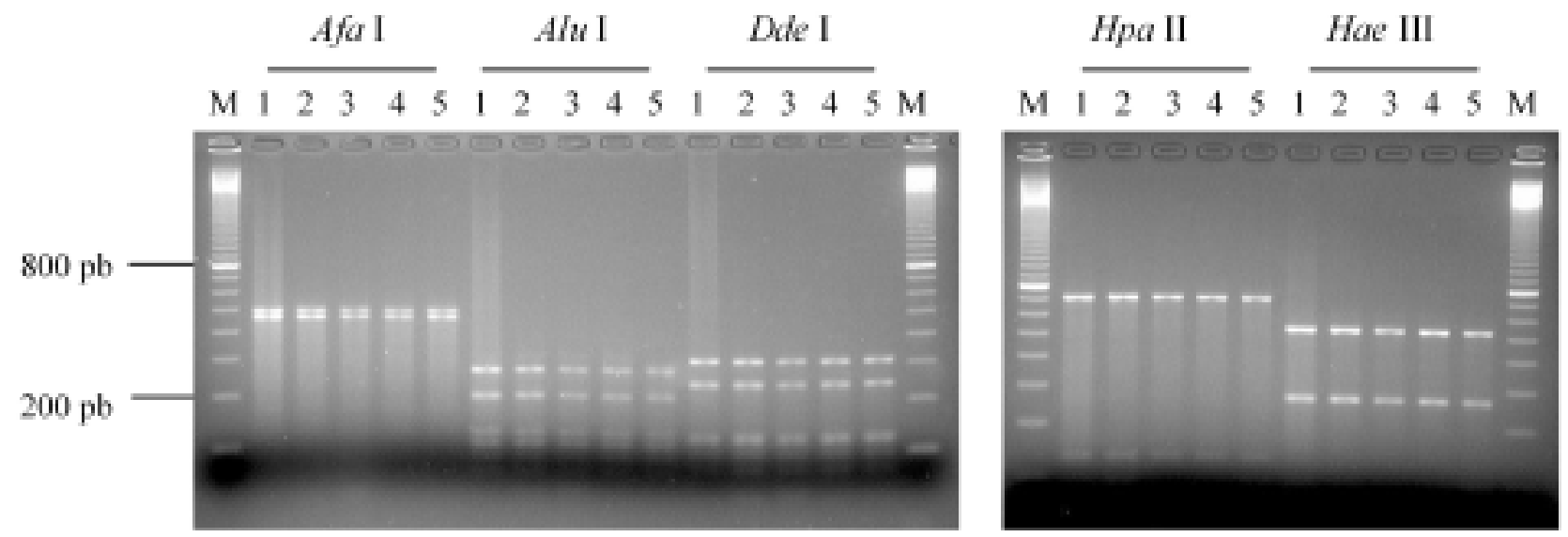

Figura 2. Digestão dos produtos de amplificação da região espaçadora $16 \mathrm{~S}-23 \mathrm{~S}$ com diferentes enzimas de restrição. (M) marcador de peso molecular de 100 pb (A mersham Biosciences); (1 a 5) IBSBF 1733", IBSBF 1911, IBSBF 1912, IBSBF 1913 e IBSBF 2003.

digestões com D de I, os fragmentos foram de 310, 240, 120 e $100 \mathrm{pb}$. H pa II e Haelll produziram fragmentos de 700 e 130 pb; e 510 e 280 $\mathrm{pb}$, respectivamente (F igura 2). Em todos os casos, as linhagens IB SB F $1911,1912,1913$ e 2003 isoladas de algodoeiro apresentaram perfis idênticos aos apresentados pela linhagem patotipo de X. a. pv. malvacearum (IBSBF 1733 ${ }^{\mathrm{P}}$.

Nos testes para avaliação de sensibilidade a antibióticos foram utilizadas as linhagens IBSB F 1911, 1912, 1913 e 2003 e os seguintes produtos, diretamente incorporados ao meio NA: 1) sulfato de estreptomicina a $15 \%$ + oxitetraciclina a $1,5 \% ; 2$ ) oxitetraciclina a 3 $\%$ + sulfato de cobre tribásico a $40 \%$; 3) oxitetraciclina a $20 \%$; e 4) kasugamicina a $2 \%$, nas concentrações de 100, 250 e 500 ppm de princípio ativo. Quatro placas por tratamento/concentração com os diferentes antibióticos foram semeadas, separadamente, utilizando-se $0,1 \mathrm{~mL}$ das suspensões bacterianas de cada linhagem (ca. $10^{8} \mathrm{UFC} / \mathrm{mL}$ ). Placas-testemunha não receberam nenhum produto. L eituras foram realizadas diariamente até 10 dias após 0 plaqueamento, sendo avaliado o crescimento ou não de colônias bacterianas. A s quatro linhagens avaliadas mostraram-se sensíveis aos produtos e às dosagens empregadas. Entretanto, considerando a existência de relatos de resistência natural a antibióticos em X. a. pv. malvacearum, entre el es a estreptomicina e a oxitetraciclina, já descritos desde a década de $60(1,2,4)$, e que em outros países antibióticos vêm sendo empregados no controle de X. a. pv. 
malvacearum, tanto no tratamento de sementes quanto em pulverização de plantas, deve-se tomar precauções para evitar seleção de populações bacterianas resistentes.

Com base nos resultados dos testes de patogenicidade, bioquímicos, culturais, sorológicos e moleculares efetuados, confirmase a identidade dos isolados como Xanthomonas axonopodis pv. malvacearum em al godoeiro, causando sintomas de crestamento foliar, além da usual mancha angular.

\section{REFERÊNCIASBIBLIOGRÁFICAS}

1. Brinkerhoff, L.A. Variability of Xanthomonas malvacearum: the cotton bacterial blight pathogen. Stillwater: Oklahoma State University, 1963. 95p. (Technical Bulletin T-98).

2. B rinkerhoff, L.A. Variation in Xanthomonas malvacearum and its relation to control. A nnual Review of Phytopathology, Palo Alto, v.8, p.85-110, 1970

3. Destéfano, S.A.L ; Rodrigues Neto, J. Rapid differentiation of
Xanthomonas strains causing disease in citrus plants based on polymerase chain reaction-amplified ribosomal dna spacer poIymorphisms. Summa Phytopathologica, v.28, n.2, p.167-172, 2002.

4. Nafade, S.D.; Verma, J.P. D rug resistant mutants of Xanthomonas campestris pv. malvacearum. Indian Phytopathology, New Delhi, v.38, p.74-80, 1985.

5. Pitcher, D.G.; Saunders, N.A., Owen, R.J. Rapid extraction of bacterial genomic DNA with guanidium thiocyanate. Letters of A pplied Microbiology, Oxford, v.8, p.151-156, 1989.

6. Pizzinatto, M.A.; M alavolta J r., V.A.; Cia, E. Crestamento foliar em algodão, novo sintoma causado por Xanthomonas axonopodis pv. malvacearum. Summa Phytopathologica, B otucatu, v.30, p.128, 2004.

7. Schaad, N.W.; Jones, J.B.; Lacy, G.H. Xanthomonas. In: Schaad, N.W.; Jones, J.B.; Chun, W. (Eds.). Laboratory guide for identification of plant pathogenic bacteria. $3^{\text {th }}$, Saint Paul: The American Phytopathological Society, 2001. p.175-200.

8. Smith, E.F. The angular leaf-spot of cotton. In: Bacterial diseases of plants. Philadel phia: W.B. Saunders, , 1920. p.314-339. 